\title{
Water oxidation and electron extraction kinetics in nanostructured tungsten trioxide photoanodes
}

Sacha Corby ${ }^{1}$, Laia Francàs ${ }^{1}$, Shababa Selim ${ }^{1}$, Michael Sachs ${ }^{1}$, Chris Blackman $^{2}$, Andreas Kafizas ${ }^{1}$, and James R. Durrant ${ }^{1}$

${ }^{1}$ The Department of Chemistry, Imperial College London, South Kensington, London, SW7 2AZ, UK

${ }^{2}$ The Department of Chemistry, University College London, Kings Cross, London, WC1H 0AJ, UK

\begin{abstract}
A thorough understanding of the kinetic competition between desired water oxidation/electron extraction processes and any detrimental surface recombination is required to achieve high water oxidation efficiencies in transition metal oxide systems. The kinetics of these processes in high Faradaic efficiency tungsten trioxide $\left(\mathrm{WO}_{3}\right)$ photoanodes $(>85 \%)$ are monitored herein by transient diffuse reflectance spectroscopy and correlated with transient photocurrent data for electron extraction. Under anodic bias, efficient hole transfer to the aqueous electrolyte is observed within a millisecond. In contrast, electron extraction is found to be comparatively slow $(\sim 10 \mathrm{~ms})$, increasing in duration with nanoneedle length. The relative rates of these water oxidation and electron extraction kinetics are shown to be reversed in comparison to other commonly examined metal oxides (e.g. $\mathrm{TiO}_{2}, \alpha-\mathrm{Fe}_{2} \mathrm{O}_{3}$ and $\mathrm{BiVO}_{4}$ ). Studies conducted as a function of applied bias and film processing to modulate oxygen vacancy density indicate that slow electron extraction kinetics result from electron trapping in shallow $\mathrm{WO}_{3}$ trap states associated with oxygen vacancies. Despite these slow electron extraction kinetics, charge recombination losses on the microsecond to second timescales are observed to be modest compared to other oxides studied. We propose that the relative absence of such recombination losses, and the observation of a photocurrent onset potential close to flat-band, result directly from the faster water oxidation kinetics of $\mathrm{WO}_{3}$. We attribute these fast water oxidation kinetics to the highly oxidising valence band position of $\mathrm{WO}_{3}$, thus highlighting the potential importance of thermodynamic driving force for catalysis in outcompeting detrimental surface recombination processes.
\end{abstract}




\section{Introduction}

Photoelectrochemical water splitting is a promising strategy for sustainable fuel generation, but the limiting kinetics of the four-hole water oxidation reaction remain a key challenge to unlocking higher efficiencies. ${ }^{1}$ Since the pioneering study on $\mathrm{TiO}_{2}$ by Fukishima and Honda in the $1970 \mathrm{~s},{ }^{2}$ transition metal oxides have remained amongst the most widely studied photoanodes for water oxidation due to their earth abundance, good aqueous stability and facile synthesis..$^{3-7}$ However, most such oxides, including $\mathrm{TiO}_{2}, \alpha-\mathrm{Fe}_{2} \mathrm{O}_{3}$, and $\mathrm{BiVO}_{4}$, demonstrate sluggish water oxidation kinetics, allowing competing recombination processes to drastically lower performance. ${ }^{8-10}$ Heterojunctions, catalysts or overlayers are then required to accelerate water oxidation kinetics and/or slow recombination, increasing cost and complexity. With a narrower band gap than $\mathrm{TiO}_{2}$, tungsten trioxide $\left(\mathrm{WO}_{3}\right)$ can absorb a larger proportion of the solar spectrum, while maintaining a deep valence band energy to provide a large thermodynamic driving force for water oxidation. ${ }^{11,12} \mathrm{WO}_{3}$ demonstrates good photocurrent onset and is also stable at acidic $\mathrm{pH}$ which allows preferential pairing with acid-stable photocathodes. ${ }^{11,13,14}$ While there exists extensive research on the semiconducting properties of $\mathrm{WO}_{3}$, particularly with respect to photo- and electrochromic phenomena, the kinetics of water oxidation on this metal oxide remain, to the best of our knowledge, largely unexplored. ${ }^{15}$ In this study, we measure the kinetics of water oxidation and electron extraction in nanostructured $\mathrm{WO}_{3}$ photoanodes, and compare these with other metal oxide photoanode materials. We reveal how these complementary processes of charge removal from the system compete with recombination on the microsecond to second timescale and enable the achievement of photocurrent onset potentials close to flatband without added co-catalysts.

$\mathrm{WO}_{3}$ is often reported to have high electrical conductivity, ${ }^{5,14,16}$ leading to its frequent implementation as an electron transport layer in various heterojunction photoanodes, including junctions formed with $\alpha-\mathrm{Fe}_{2} \mathrm{O}_{3}$ and $\mathrm{BiVO}_{4}$, in which conductivity is significantly poorer. ${ }^{11,12,17-21}$ It is proposed that high electrical conductivity improves water splitting performance by aiding the separation of photogenerated charges such that competing recombination processes are retarded. ${ }^{22}$ High conductivity in $\mathrm{WO}_{3}$ is considered to be a result of a large density of charge carriers, caused by intrinsic oxygen vacancies, which act as n-type dopants. ${ }^{23-25}$ Carrier concentrations in the range of $10^{17}$ to $10^{22} \mathrm{~cm}^{-3}$ have been reported, depending on stoichiometry $\left(\mathrm{WO}_{3-\mathrm{x}}\right) .{ }^{11,26,27}$ Similarly, changes in the stoichiometry of single crystals have been shown to modulate electrical conductivity between $10-10^{-4} \mathrm{~S} / \mathrm{cm} .{ }^{23}$ However, such deviations from stoichiometry have also been suggested to introduce chemical defects that can result in increased charge trapping which, rather than boost performance, can often introduce additional recombination pathways. ${ }^{28-32}$ For example, the presence of defect states in the band gap of $\alpha-\mathrm{Fe}_{2} \mathrm{O}_{3}$ has been shown to enhance electron-hole recombination kinetics that can outcompete water oxidation. ${ }^{33}$ In addition, high carrier densities can also 
result in shorter minority carrier lifetimes and thus also accelerated recombination losses. ${ }^{34,35}$ Water oxidation is a kinetically slow process, requiring the accumulation of multiple holes. As such, kinetic competition between water oxidation/electron extraction and surface charge recombination (sometimes called back electron-hole recombination) can severely limit the efficiency of photoelectrochemical water oxidation. ${ }^{36-39}$ Using sacrificial reagents, Amano et al found that the size of suspended $\mathrm{WO}_{3}$ particles affected the frequency of surface recombination with concurrent effects on oxygen evolution rate. ${ }^{40}$ However, this competition has received limited attention to date for $\mathrm{WO}_{3}$ photoanodes under photoelectrochemical conditions.

Reported herein is an analysis the dynamics of photogenerated charges in tungsten oxide photoanodes synthesised by chemical vapour deposition (CVD). The synthesis method generates highly oxygen deficient monoclinic $\mathrm{WO}_{3-\mathrm{x}}$ nanoneedle structured films that are intensely blue in colour, which are then annealed in air at elevated temperature to remove most of the oxygen vacancies. These photoanodes exhibit an early photocurrent onset potential ( $c a 0.5 \mathrm{~V}$ vs RHE) and a high Faradaic efficiency for water oxidation (>85\%). The rate of water oxidation is analysed by transient diffuse reflectance spectroscopy and transient photocurrent measurements and is found to be faster than other commonly used transition metal oxides, and much faster than electron extraction. The effect of interband defects on electron transport is then investigated. We find that electron trapping in the $\mathrm{WO}_{3}$ needles is significant and propose a trap-mediated mechanism of electron transport to the back contact (FTO). To examine how the density of traps may affect this electron transport, we alter the annealing time and the needle length, and find that this has profound effects on extraction time. We thus provide unique kinetic insight on the charge carriers of $\mathrm{WO}_{3}$, a material growing in popularity for solar fuel related applications, ${ }^{41-45}$ and highlight the direct impact these kinetics have on photoelectrochemical performance. 


\section{Results}

\section{Sample Characterisation}

Tungsten oxide samples were prepared by aerosol assisted chemical vapour deposition (AA-CVD) according to a previously established synthesis ${ }^{46}$ as detailed in the Supporting Information (SI, Methods). Figure 1a shows the cross-sectional SEM image of an annealed $\mathrm{WO}_{3}$ sample, indicating the 4-micron long needles (yellow line) on top of the dense seed layer (400 nm, red line). X-ray diffraction data confirms the crystalline monoclinic nature of these $\mathrm{WO}_{3}$ films, with the (002) peak most prominent due to the preferential growth along this axis (Supporting information, $\mathrm{S} 1$ ).
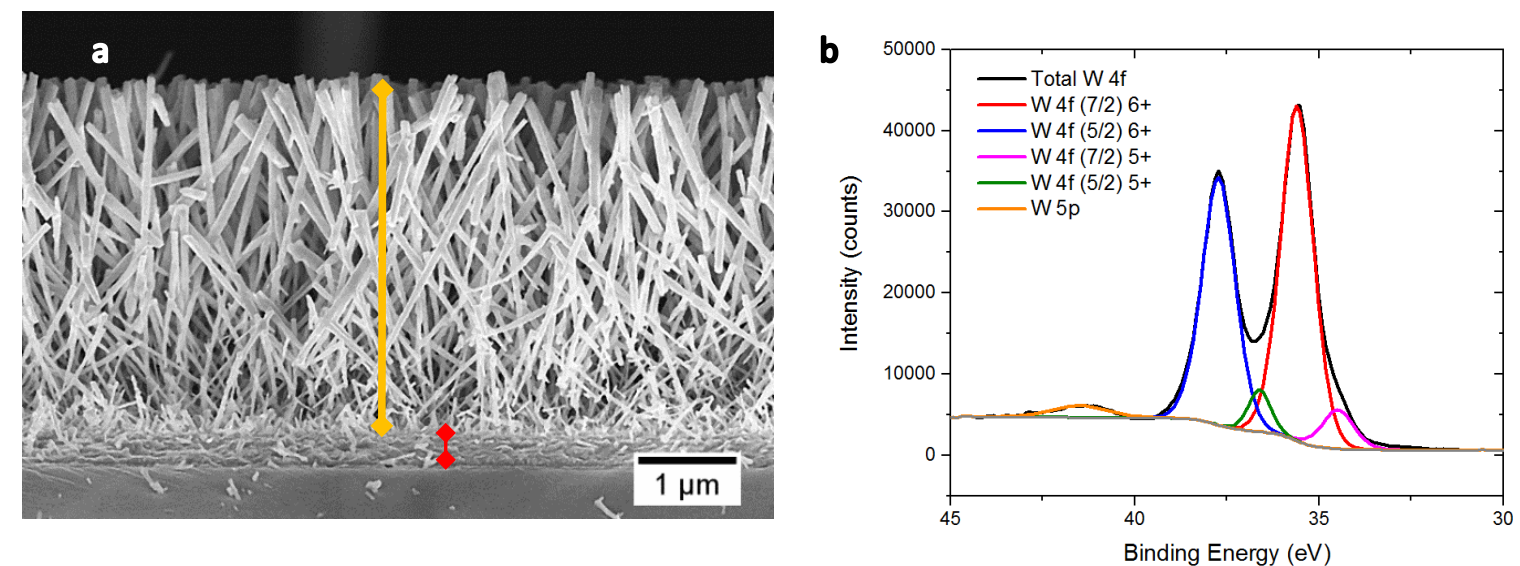

Figure 1: (a) Cross-sectional SEM image of annealed $\mathrm{WO}_{3}$ needles ( $3.6 \mu \mathrm{m}$, yellow line) on $400 \mathrm{~nm}$ dense $\mathrm{WO}_{3}$ seed layer (red line) deposited on FTO coated glass, $53 \mathrm{~K}$ magnification. (b) High resolution $\mathrm{W} 4 \mathrm{f}$ XPS scan indicating a small proportion of $\mathrm{W}^{5+}$ states.

Samples were also characterised by X-ray photoelectron spectroscopy (XPS). The XPS spectra of $\mathrm{WO}_{3}$ samples before and after annealing indicate the films are of similar purity, with adventitious carbon the only detectable impurity (Figure S2b). The W 4f peaks in the un-annealed, blue sample show significant shoulders at lower binding energy as a result of a large number of $\mathrm{W}^{5+}$ species present, which can be directly correlated with oxygen vacancies (Figure S2c). The proportion of $\mathrm{W}^{5+}$ to $\mathrm{W}^{6+}$ analysed with this surface sensitive technique is approximately $30 \%$. Figure $1 \mathrm{~b}$ shows that after annealing in air at 500 degrees for 2 hours, the number of these reduced states is dramatically decreased to approximately $10 \%$ of the tungsten atoms probed. Photographs of the annealed and un-annealed samples are given in Figure S2a. 


\section{Photoelectrochemical water splitting performance}

The current-voltage characteristics of annealed $\mathrm{WO}_{3}$ were examined by linear sweep voltammetry under chopped simulated 1 sun irradiation from the front side (EE), as shown in Figure 2. As highlighted in Figure S3, the dark current was negligible over the voltage range examined, as was the photocurrent for the unannealed sample. As shown in Figure 2, the photocurrent reaches a plateau around $1.23 \mathrm{~V}_{\text {RHE }}\left(\sim 0.4 \mathrm{~mA} / \mathrm{cm}^{2}\right)$, and the onset potential ( $c a 0.5 \mathrm{~V}_{\mathrm{RHE}}$ ) is only approximately $100 \mathrm{mV}$ above the calculated flat-band for such nanostructured $\mathrm{WO}_{3}{ }^{47}$ Unlike photoanodes of several other transition metal oxides, there is an absence of transient spikes when the light is turned on (positive spikes) or off (negative spikes). Such photocurrent transients are indicative of current loss from recombination processes at the surface, typically the recombination of surface accumulated holes with bulk electrons, which compete with hole transfer to the electrolyte (e.g. by water oxidation). ${ }^{36,48}$ These transients are readily observed in $\alpha-\mathrm{Fe}_{2} \mathrm{O}_{3}$ and $\mathrm{BiVO}_{4}$, for which this recombination can be a significant loss pathway. ${ }^{49,50}$ The early photocurrent onset observed for the $\mathrm{WO}_{3}$ needles combined with the lack of transient current spikes suggests that there is very little such surface recombination occurring, which may be a result of slower surface recombination or a faster reaction of accumulated holes, as we discuss further below. Oxygen evolution was measured with a calibrated Clark electrode as detailed in the SI. Figure S4 demonstrates the high Faradaic efficiencies obtained which were consistently between $85-90 \%$. We note this to be higher than a large proportion of the Faradaic efficiency values reported in the literature for this material. ${ }^{14,25,39}$ This high Faradaic efficiency may be related to the high crystallinity of the $\mathrm{WO}_{3}$ needles and/or preferential crystal orientation, reported by others to be significant. ${ }^{40,51}$ Further analysis on this aspect is, however, beyond the scope of this kinetic study.

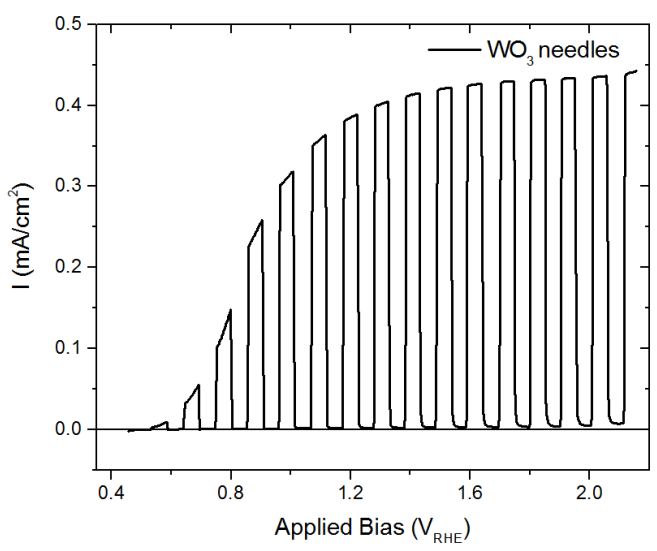

Figure 2: Chopped light linear sweep voltammetry, in $0.5 \mathrm{M} \mathrm{H}_{2} \mathrm{SO}_{4}$, of $\mathrm{WO}_{3}$ needles under 1 sun conditions, indicating early photocurrent onset and reasonable maximum. Details of the 3 -electrode set up can be found in the SI. 


\section{Dynamics of electrons and holes}

Transient diffuse reflectance spectroscopy (TDRS) measurements were performed on the microsecond to second timescale to monitor the kinetics of photogenerated charges under water oxidation conditions (see Supporting Information for details). Previous studies have shown that $\mathrm{WO}_{3}$ exhibits two main spectral features: a broad transient signal centred at around $800 \mathrm{~nm}$ which, by use of chemical scavengers, has been assigned to photoexcited electrons around the conduction band; and a hole signal, which may be probed below $550 \mathrm{~nm} .{ }^{52}$ The transient diffuse reflectance spectra for the $\mathrm{WO}_{3}$ needles in this work, Figure $3 \mathrm{a}$, are in agreement with these previous assignments. The stronger electron absorbance signal spans most of the visible spectrum down to approximately $550 \mathrm{~nm}$. Monitoring the electrons at $800 \mathrm{~nm}$, we observe a long lived transient signal that decays by approximately 1 second (black trace, Figure 3b). The transient photocurrent (TPC) was measured simultaneously and integrated to give the extracted electron density as a function of time delay (dashed blue trace, Figure 3b). By comparing the TDRS electron signal at $800 \mathrm{~nm}$ with the integrated TPC signal, it is clear that the integrated TPC signal rises as the $800 \mathrm{~nm}$ signal decays, supporting the assignment of the $800 \mathrm{~nm}$ TDRS signal to $\mathrm{WO}_{3}$ electrons. On the other hand, the hole signal, monitored at $500 \mathrm{~nm}$, presents a much faster decay, implying faster kinetics for the hole reaction with the electrolyte. Given the high Faradaic efficiency exhibited by this photoanode, this hole reaction can be assigned primarily to water oxidation. If we take approximate half-times for these decays with respect to the signal amplitude at $10 \mu \mathrm{s} ; \mathrm{t}_{1 / 2}$ (electrons) is $\sim 10 \mathrm{~ms}$ and $\mathrm{t}_{1 / 2}$ (holes) is $\sim 0.5 \mathrm{~ms}$. These values indicate that holes react an order of magnitude faster than electrons are extracted by the external circuit. As will be highlighted in more detail in the following sections, this timescale of water oxidation is much faster than those observed for other commonly studied transition metal oxides. ${ }^{8,10,53}$
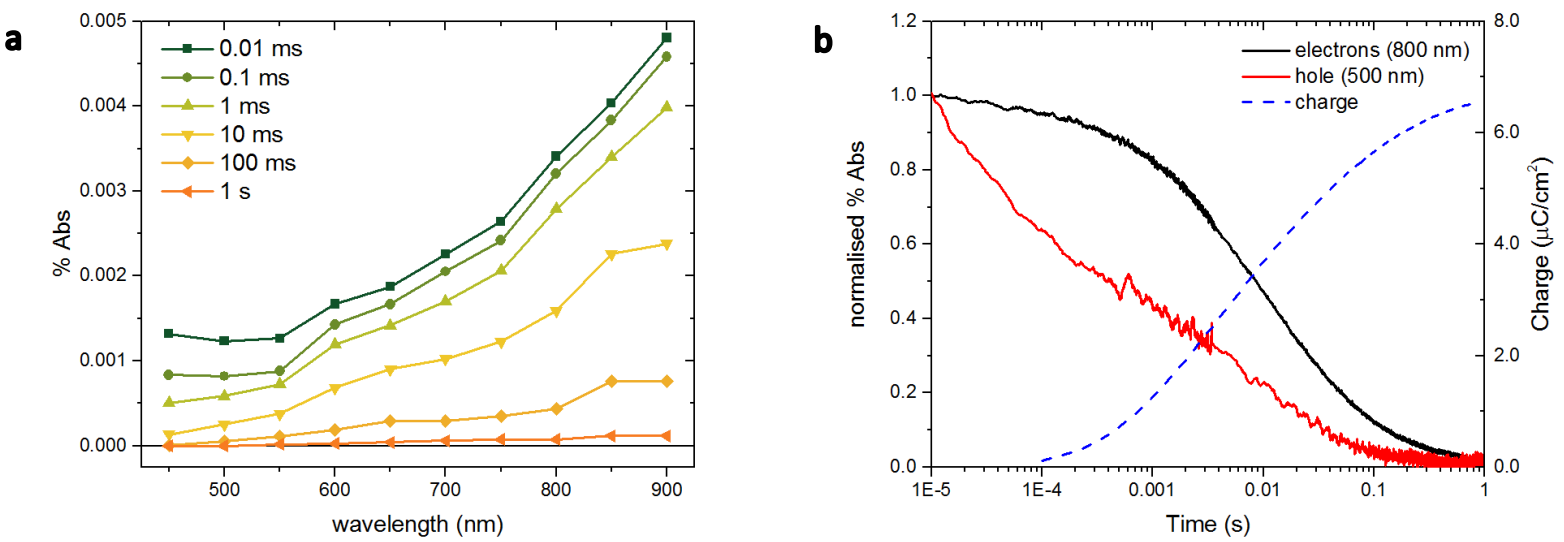

Figure 3: Transient diffuse reflectance data of $\mathrm{WO}_{3}$ photoanode at $1.45 \mathrm{~V}_{\mathrm{RHE}}$ in $\mathrm{pH} 1$ electrolyte, $355 \mathrm{~nm}$ excitation at $0.3 \mathrm{~mJ} / \mathrm{cm}^{2}$ and $0.4 \mathrm{~Hz}$. (a) transient spectra for time delays after photoexcitation from 0.01 
ms to $1 \mathrm{~s}$, and (b) kinetic traces at $800 \mathrm{~nm}$ (black) and at $500 \mathrm{~nm}$ (red), assigned to electron and hole signals, respectively, alongside integrated transient photocurrent data (dashed blue) corresponding to the kinetics of electron extraction to the external circuit.

\section{Hole kinetics in water and propylene carbonate}

To further examine the rapid water oxidation kinetics evident from the TDRS decay at $500 \mathrm{~nm}$ in Figure 2, the same kinetic measurement was repeated in inert organic solvent (propylene carbonate). As seen in Figure 4 (red trace), when there is no water present, a longer lived transient signal is observed at $500 \mathrm{~nm}$. This trace still decays within the timescale of the measurement due to some oxidation of the solvent and/or other recombination processes. When a small percentage of water ( $\mathrm{pH} 1$ electrolyte) is added to the electrolyte, the rate of signal decay is increased, thus confirming that the fast decay observed at $500 \mathrm{~nm}$ is due to surface holes reacting with water. Although the poor miscibility of water in propylene carbonate limits our comparisons to low water concentrations, a clear trend of increasing rate with increasing water content is observed, with the $100 \%$ aqueous electrolyte displaying the fastest oxidation kinetics.

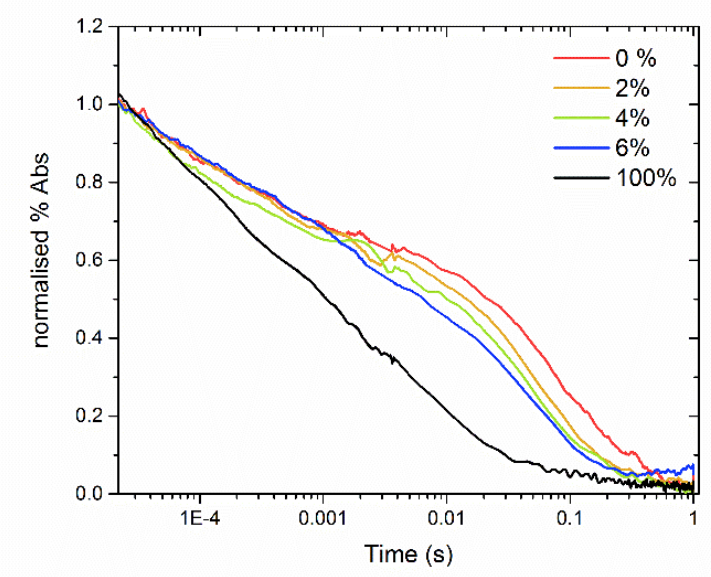

Figure 4: TDR decay traces for $\mathrm{WO}_{3}$ needles at $1.45 \mathrm{~V}_{\mathrm{RHE}}$ in propylene carbonate $\mathrm{TBA} \mathrm{SO}_{4}$, with increasing aqueous electrolyte volume fraction $\left(0.1 \mathrm{M} \mathrm{H}_{2} \mathrm{SO}_{4}, \%\right)$, probed at $500 \mathrm{~nm}$.

\section{$\underline{\text { Kinetics of electron transport }}$}

To further investigate the relatively slow electron extraction kinetics observed from the $800 \mathrm{~nm}$ TDRS and TPC data in Figure 3, a series of transient diffuse reflectance decays were recorded at a range of potentials, along with integrated transient photocurrent signals, to determine the effect of applied bias (Figure 5a). 
With progressively larger anodic bias, the magnitude of the initial optical and final extracted charge signals increase simultaneously. The rise in these signal amplitudes indicates an increase in the density of photogenerated long-lived electrons that can be extracted to the external circuit. This can be rationalised as a consequence of greater band bending in the material under higher bias, creating a larger space charge layer to separate charges and thus a higher yield of electrons. In other words, the magnitude of the optical signal directly correlates to the number of electrons that remain in the electrode after any ultrafast bulk recombination occurs. In Figure 5b, we plot the correlation between our initial optical TDRS assay of long lived electrons (green triangles) and our integrated photocurrent assay of extracted electrons (blue circles) versus applied potential. The close agreement between these two assays indicates that, despite the slow electron extraction kinetics, the electrons observed on these timescales are still extracted reasonably efficiently by the external circuit, i.e. relatively few of the electrons monitored on the micro- to second timescales studies herein are recombining on this timescale. This is in agreement with the early photocurrent onset and lack of transient spikes observed in the chopped J-V curve (Figure 2a). If we consider the extracted charge density at both $50 \mathrm{~ms}$ (Figure 6b, pink squares) and $1 \mathrm{~s}$ (blue circles), we observe a small difference at low bias indicative of modest back electron-hole recombination losses. Back electron-hole (surface) recombination occurs over long timescales as a result of charge accumulation at the electrodeelectrolyte interface. This build-up of charge draws electrons in the opposite direction of normal current flow, diminishing the total charge collected. ${ }^{36}$ By $1.15 \mathrm{~V}_{\mathrm{RHE}}$, a large enough field is maintained to successfully prevent this slow timescale recombination process. This 'surface recombination turnoff' potential is lower than for $\alpha-\mathrm{Fe}_{2} \mathrm{O}_{3}$ and $\mathrm{BiVO}_{4}$ photoanodes, ${ }^{8,36,54,55}$ most probably due to the faster competing water oxidation reaction kinetics reported above. Applied potentials $\geq 1.15 \mathrm{~V}_{\mathrm{RHE}}$ result in increased charge extraction with time, as the majority of electrons are collected.

Figure $5 \mathrm{c}$ and d give, respectively, the normalised optical and photocurrent (without integration) transients for a series of applied biases. We note that increasing bias results in longer lived optical signals, and slower charge extraction kinetics. This could be a result of improved charge separation, although, as mentioned, there is little recombination at these timescales as most charges are extracted. Alternatively, and more likely, these slower kinetics under stronger anodic bias could result from increased trapping of charges with larger bias, resulting in hindered transport. It is widely acknowledged that $\mathrm{WO}_{3}$ has a large propensity to form electronic defects within the band gap. ${ }^{24,29,56-58}$ With the conduction and valence band energies pinned at the electrolyte interface, increases in applied potential could empty, and thus make available for electron trapping, an increasing density of unoccupied shallow defect states within the space charge layer. This would slow extraction as electrons would encounter a greater number of progressively deeper states with increasing positive bias. This is analysed further in the discussion section below. 
a

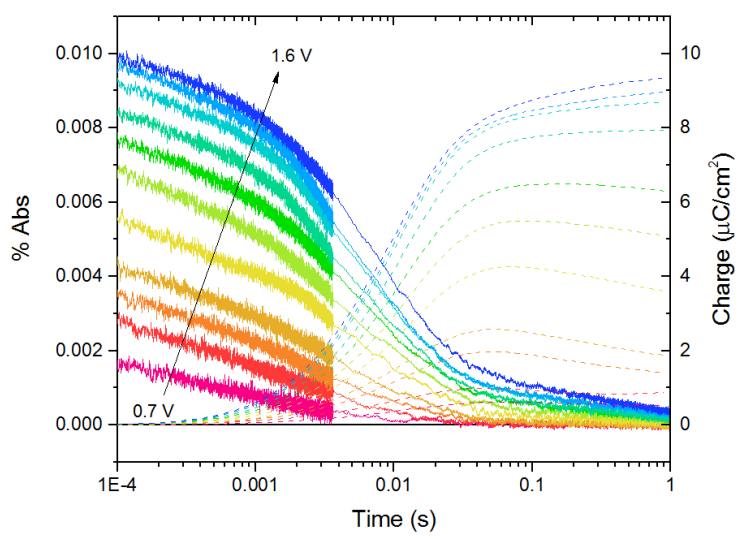

c

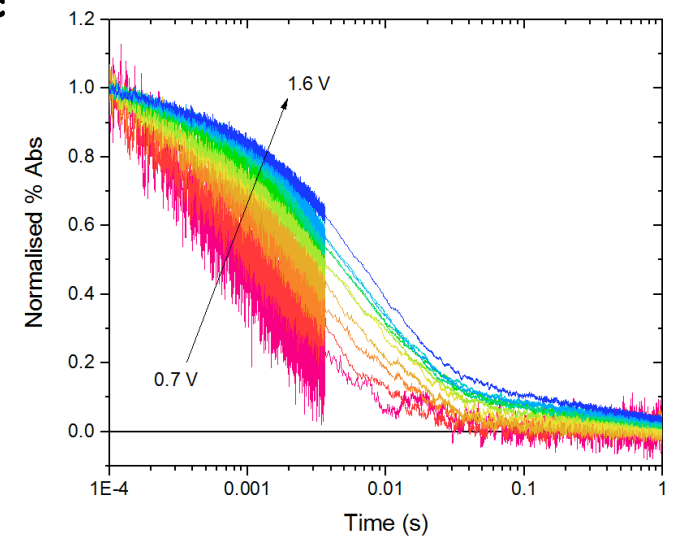

b

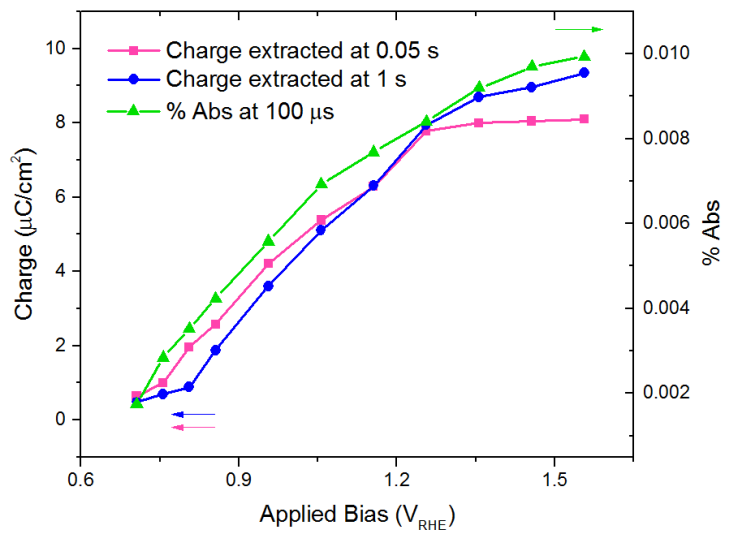

d

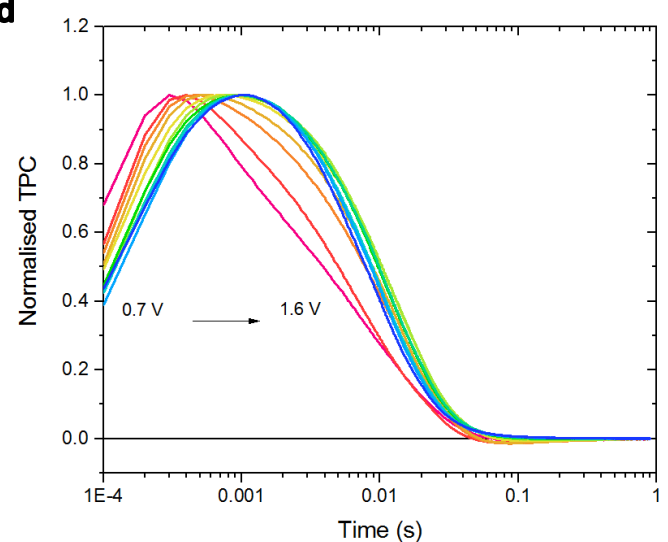

Figure 5: (a) TDR decays at $800 \mathrm{~nm}$ and the integrated transient photocurrent at a range of different applied potentials $\left(0.7-1.6 \mathrm{~V}_{\mathrm{RHE}}\right)$. (b) The initial magnitude of the optical signal (green triangles), and the extracted charge measured at $50 \mathrm{~ms}$ (pink squares) and at the end of the measurement, $1 \mathrm{~s}$, (blue circles). (c) Normalised optical decays shown in (a). (d) Normalised transient photocurrents for the same applied potentials.

Incident photon to current efficiency (IPCE) measurements were conducted at $1.23 \mathrm{~V}_{\mathrm{RHE}}$ with front and back irradiation to probe whether slow electron extraction is limiting performance (SI, Figure S5a). With FTO absorption accounted for in both cases, higher efficiencies were obtained when the needles were irradiated from the back ( $36 \%$ vs $22 \%$ at $350 \mathrm{~nm}$ ), with charges generated closer to the extraction point. This correlates with the slow extraction times observed by TDRS and suggests that the small amount of 
surface or back electron-hole recombination observed (Figure 5) has some effect on performance. The trend in IPCE also agrees with the relatively large diffusion length of holes $(150 \mathrm{~nm})$ in $\mathrm{WO}_{3}$, which has previously been reported to be significantly larger than for other popular metal oxides (e.g. $\sim 4 \mathrm{~nm}$ in $\alpha$ $\mathrm{Fe}_{2} \mathrm{O}_{3}$ ), sometimes larger than the depletion width. ${ }^{5,21,28}$ Since the $\mathrm{WO}_{3}$ needles are approximately $100 \mathrm{~nm}$ in diameter, holes may readily diffuse to the surface regardless of whether the electrode is irradiated from the front or the back. IPCE data was also collected over longer wavelengths to confirm that any absorption from oxygen vacancies does not contribute to enhanced visible light harvesting (Figure S5b).

\section{$\underline{\mathrm{WO}_{3}}$ modifications}

To aid confirmation of the cause of such slow electron extraction kinetics, various alterations were made to the $\mathrm{WO}_{3}$ needles. The first was to grow shorter needles ( 2 micrometres) through modification of the same AACVD synthesis. ${ }^{46}$ As is apparent in Figure 6a, the shorter $\mathrm{WO}_{3}$ needles give a faster optical electron signal decay (blue line) and earlier charge extraction kinetics (dashed lines), indicating that electron extraction is kinetically limited by electron transport through the $\mathrm{WO}_{3}$ needles. Front and back IPCE are more comparable for these shorter needles as the electron transport distance has been reduced (Figure S6).

The second modification was to anneal the as-synthesised blue $\mathrm{WO}_{3-\mathrm{x}}$ needles in air for a longer period of time. We have already confirmed through XPS that annealing in air reduces the number of oxygen vacancies (Figure S2b versus Figure 1b). Similarly, observations in literature show that the converse approach of annealing under oxygen-poor atmosphere (hydrogen or argon) increases the number of oxygen vacancies, ${ }^{13}$ which may act as electron trap sites. ${ }^{59}$ Although the nature of any trap sites discussed herein have not been probed directly, it is reasonable to assume that these would be associated with oxygen vacancies as evidenced by our XPS measurements (Figure $1 \mathrm{~b}$ ) and the wealth of data on $\mathrm{WO}_{3} .{ }^{56,57,60,61}$ Figure $6 \mathrm{~b}$ compares the electron decay of a long needle sample annealed in air at $500^{\circ} \mathrm{C}$ for 2 hours to one annealed for 12 hours, and thus with a reduced population of oxygen vacancies. This subtle change in oxygen vacancy density was determined by an increase in sub-bandgap polaron absorption (Figure S7), as previously reported in the literature. ${ }^{26,62,63}$ As can be observed, the half-lifetimes of both the TDRS and photocurrent decays are reduced for the sample that was annealed for a longer period of time, consistent with the idea of trap states associated with oxygen vacancies slowing electron extraction. 

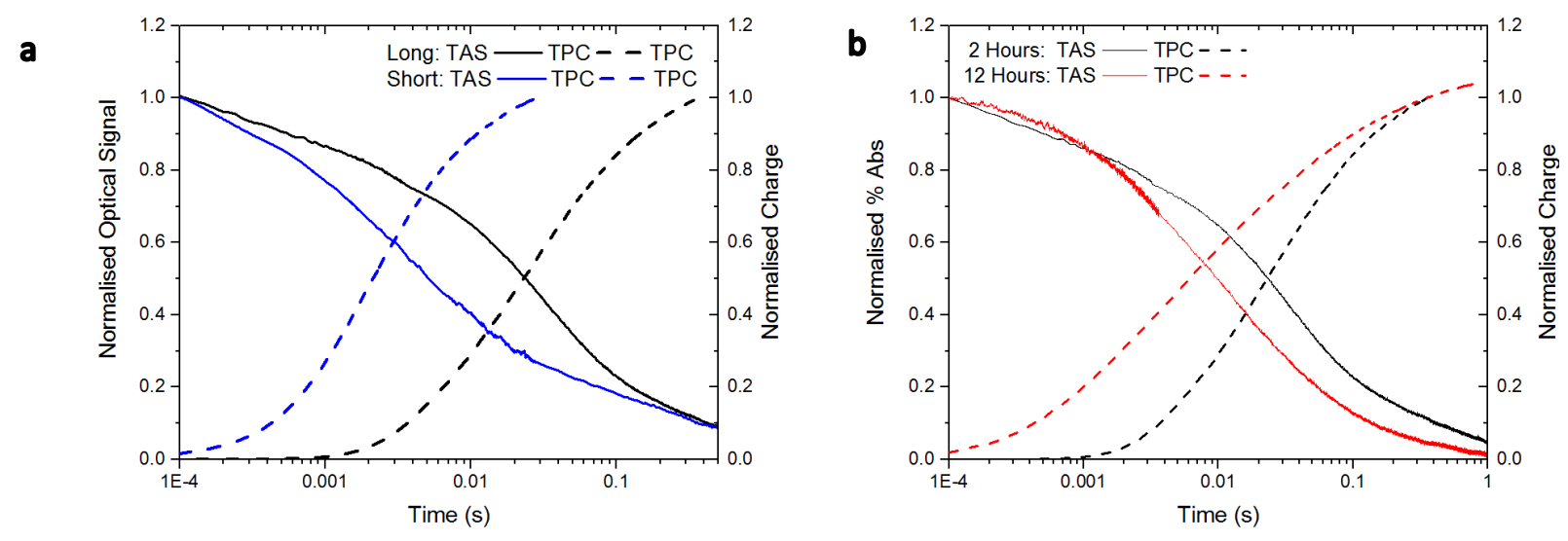

Figure 6: TDR decays at $800 \mathrm{~nm}$ (solid lines) and corresponding TPC data (dashed lines) at $1.45 \mathrm{~V}_{\mathrm{RHE}}$, $\mathrm{pH} 1$ electrolyte. (a) Comparison of $\mathrm{WO}_{3}$ needles with shorter $\mathrm{WO}_{3}$ needles grown by the same method; (b) comparison of $\mathrm{WO}_{3}$ needles to those annealed in air for a longer time to remove/fill more oxygen vacancies. 


\section{Comparisons with other transition metal oxides}

We finally compare the kinetics of water oxidation and electron extraction reported herein for $\mathrm{WO}_{3}$ with other transition metal oxides frequently employed as photoanodes for water splitting.
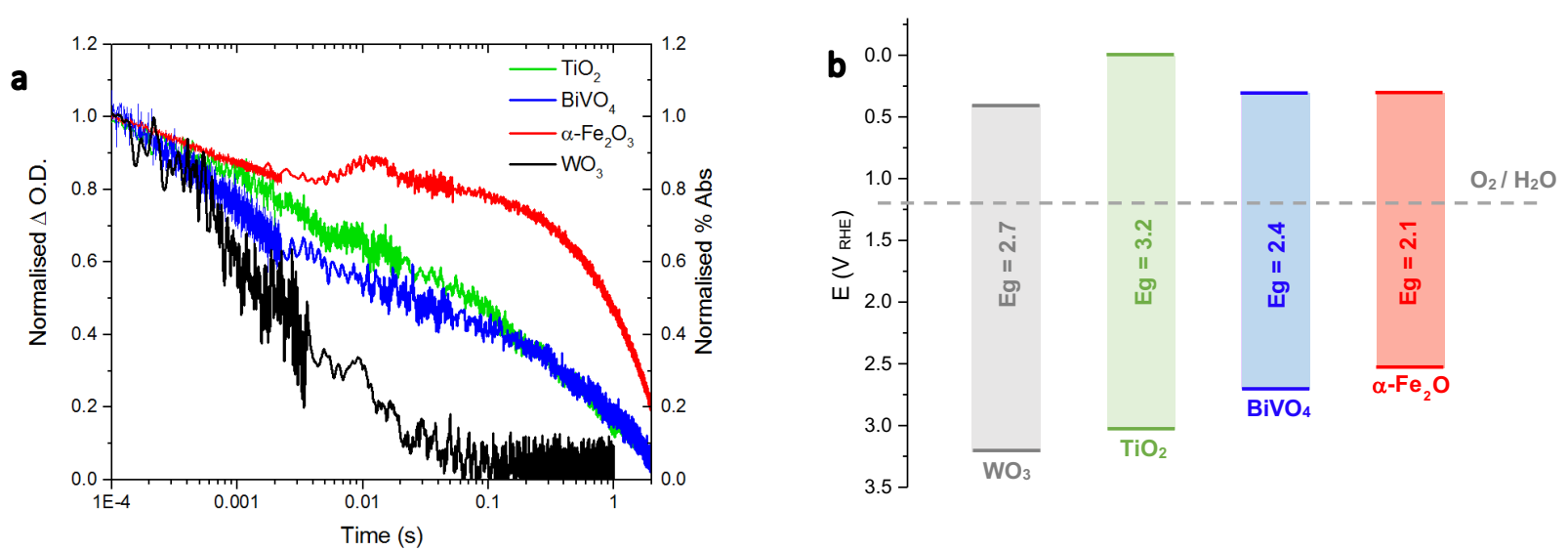

Figure 7: TDR decay traces for holes in the $\mathrm{WO}_{3}$ needles (black), studied at $500 \mathrm{~nm}\left(\mathrm{pH} 1,1.45 \mathrm{~V}_{\mathrm{RHE}}\right.$ ), compared to transient absorption measurements of hole decays in other transition metal oxides at similar applied bias, equating to the photocurrent plateau: $\mathrm{BiVO}_{4}$ in blue (550 nm, pH 7, $\left.1.5 \mathrm{~V}_{\mathrm{RHE}}\right), \mathrm{TiO}_{2}$ in green (500 nm, pH 13, $1.15 \mathrm{~V}_{\text {RHE }}$ ), and $\alpha-\mathrm{Fe}_{2} \mathrm{O}_{3}$ in red $\left(650 \mathrm{~nm}, \mathrm{pH} 13,1.5 \mathrm{~V}_{\text {RHE }}\right)$. (b) Valence band alignments for the different metal oxides. ${ }^{17,19,64}$

In Figure $7 \mathrm{a}$, the transient optical signal for water oxidation by surface holes is compared between transition metal oxides commonly studied as photoanodes for water oxidation. Often considered the kinetic bottleneck of photoelectrochemical water splitting, the oxidation of water occurs on the timescale of 100 milliseconds to seconds for titania $\left(\mathrm{TiO}_{2}\right)$, hematite $\left(\alpha-\mathrm{Fe}_{2} \mathrm{O}_{3}\right)$ and bismuth vanadate $\left(\mathrm{BiVO}_{4}\right)$ but is significantly faster for the $\mathrm{WO}_{3}$ needle sample under similar applied bias. This trend can largely be correlated with the depth of the valence band (Figure $7 \mathrm{~b}$ ), with $\mathrm{WO}_{3}$ displaying the most positive valence band energy and thus the largest thermodynamic driving force for water oxidation. 

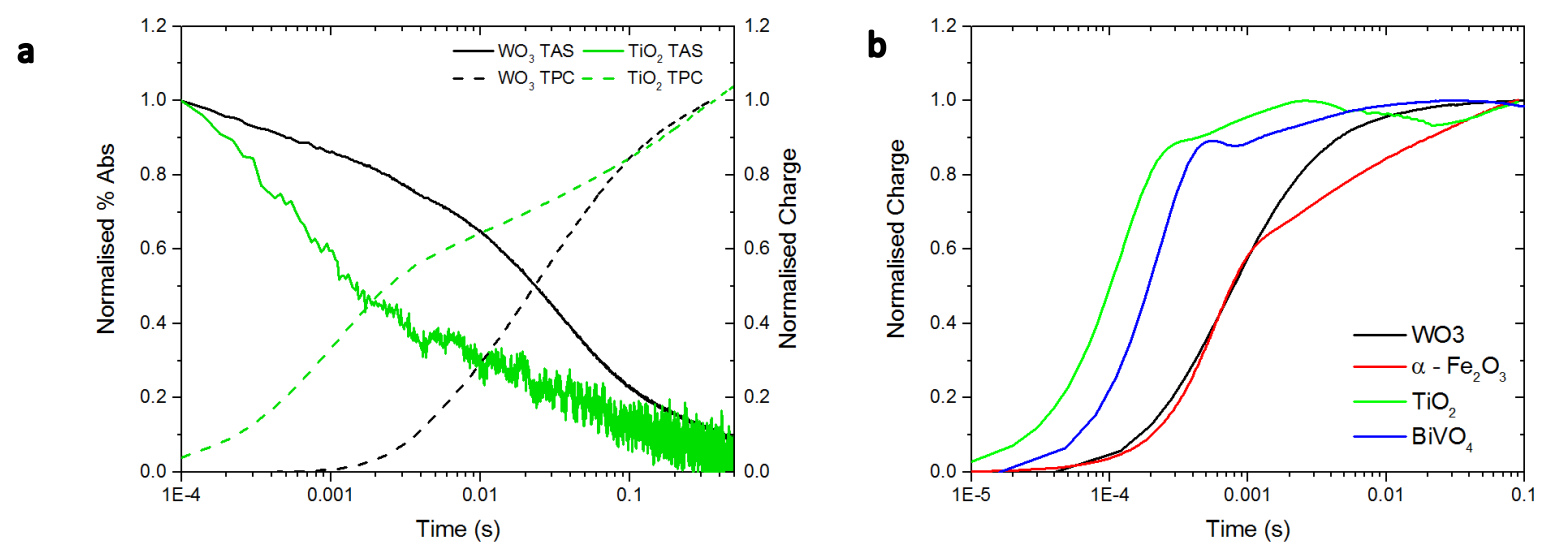

Figure 8: (a) Comparison of TDR decays at $800 \mathrm{~nm}$ (solid lines) and corresponding TPC data (dashed lines) at $1.45 \mathrm{~V}_{\mathrm{RHE}}, \mathrm{pH} 1$ electrolyte for $\mathrm{WO}_{3}$ needles (black) against $\mathrm{TiO}_{2}$ needles (green) of similar length, also grown by CVD. (b) Comparison of flat, dense $\mathrm{WO}_{3}$ (black trace, $\mathrm{pH}$ 1) with similar thicknesses of dense $\mathrm{TiO}_{2}$ (green trace, $\mathrm{pH}$ 13), $\mathrm{Fe}_{2} \mathrm{O}_{3}$ (red trace, $\mathrm{pH}$ 13) and $\mathrm{BiVO}_{4}$ (blue trace, $\mathrm{pH}$ 7).

We also compared the electron extraction kinetics, observed both optically and by integrated photocurrent transients, of the $\mathrm{WO}_{3}$ needles studied herein to $\mathrm{TiO}_{2}$ needles of similar length (Figure 8a). ${ }^{65}$ It is clear that the electron extraction is much faster for the $\mathrm{TiO}_{2}$ sample, with a reduction in half-life of the decay from $\sim 20 \mathrm{~ms}$ to $\sim 1 \mathrm{~ms}$. Using dense samples for ease of synthesis, Figure $8 \mathrm{~b}$ gives a similar comparison of charge extraction for $\mathrm{WO}_{3}$ versus dense $\mathrm{TiO}_{2}, \alpha-\mathrm{Fe}_{2} \mathrm{O}_{3}$ and $\mathrm{BiVO}_{4}$. Once again, we observe the slowest extraction times for the $\mathrm{WO}_{3}$ sample, finding it similar to $\alpha-\mathrm{Fe}_{2} \mathrm{O}_{3}$ which is known to have low conductivity across such thicknesses when undoped $(500 \mathrm{~nm}) .^{21,66,67}$ This strongly suggests that slow electron transport is an intrinsic property of $\mathrm{WO}_{3}$. As suggested above, this is most likely related to its propensity to become oxygen deficient, forming vacancies that can trap charges. ${ }^{28,68}$ 


\section{Discussion}

In the majority of photoelectrochemical systems examined for water oxidation, the water oxidation reaction itself is considered the kinetically limiting step whereas the extraction of the majority carrier (electrons) is comparatively fast. ${ }^{10,69,70}$ However, in this work on $\mathrm{WO}_{3}$ photoanodes, we find the converse to be true. Direct analysis of transient photocurrent alongside the correlating optical decay of the electron signal has highlighted the extraction of electrons to be particularly slow, slower than the rate of water oxidation (Figure 3b). Rather surprisingly, we find evidence that holes in these nanostructured samples react faster at the electrolyte interface than for any other transition metal oxide we have previously investigated (Figure 7a), with an optical half-lifetime under bias of less than a millisecond $\left(\mathrm{t}_{1 / 2}\left(\mathrm{~h}^{+}\right) \sim 0.5 \mathrm{~ms}\right)$. Such rapid decay of hole signals in $\mathrm{WO}_{3}$ has been observed previously by Cristino et al. but was assigned to non-faradaic oxidation processes rather than water oxidation. ${ }^{39}$ Water oxidation was confirmed to be the dominant oxidation process at the surface of our $\mathrm{WO}_{3}$ needles through oxygen evolution measurements yielding $>85$ $\%$ Faradic efficiency.

The importance of fast water oxidation kinetics is most apparent in the early onset of the photocurrent for this material (Figure 2), requiring a much smaller overpotential for water oxidation compared to $\alpha-\mathrm{Fe}_{2} \mathrm{O}_{3}$ and $\mathrm{BiVO}_{4}{ }^{8,71} \mathrm{In}$ the case of $\alpha-\mathrm{Fe}_{2} \mathrm{O}_{3}$, it has been suggested that the requirement for overpotentials as large as $0.6 \mathrm{~V}$ above flat-band are the result of poor water oxidation kinetics, ${ }^{48,54,72}$ necessitating the use of cocatalysts to lower the onset potential. ${ }^{48,73,74}$ In this study, the earlier onset of $\mathrm{WO}_{3}$, presented herein and observed by others, ${ }^{11}$ correlates with faster water oxidation kinetics. Rapid reaction kinetics at the interface allow an increased proportion of holes that reach the surface to perform useful chemistry over competing back electron-hole recombination processes. This is true for our $\mathrm{WO}_{3}$ nanoneedles without the need for cocatalysts or passivating overlayers. As shown in Figure 7b, the valence band edge is more positive in $\mathrm{WO}_{3}$ than in $\mathrm{BiVO}_{4}, \alpha-\mathrm{Fe}_{2} \mathrm{O}_{3}$, and $\mathrm{TiO}_{2},{ }^{12,17,19,64,75}$ which may explain the origin of the faster water oxidation kinetics observed, given the excess thermodynamic driving force then available for the reaction to occur on $\mathrm{WO}_{3}$. This relationship between valence band depth and kinetics has been proposed in other work, ${ }^{10,76}$ and would then suggest that there exists a valence band energy dependence on photoelectrochemical water oxidation that is analogous to the overpotential dependence often found in electrocatalytic water oxidation systems. The high crystallinity of the sample, the preferential growth orientation of the needles, or effects of $\mathrm{pH}$ on the water oxidation mechanism may also contribute to the faster kinetics observed for our $\mathrm{WO}_{3}$, though further investigation on these aspects is beyond the scope of this study.

In stark contrast to the hole kinetics, when a similar comparison is made between $\mathrm{WO}_{3}$ electron dynamics and those of other transition metal oxides, we find that $\mathrm{WO}_{3}$ displays slower electron extraction (Figure 8). This difference in extraction time is as large as an order of magnitude when comparing $\mathrm{TiO}_{2}$ and $\mathrm{WO}_{3}$ 
needles and is still evident when comparing the dense films, demonstrating that slow electron extraction is a property of $\mathrm{WO}_{3}$. Considering that good electron conductivity is often presented as a promising feature of $\mathrm{WO}_{3},{ }^{5,14,16}$ this result was surprising. It suggests that the main benefit of adding $\mathrm{WO}_{3}$ as an electron transport layer in various heterojunctions is to aid charge separation and thus increase charge carrier lifetime, rather than rapidly transport electrons to the contact. Irradiated from the front, we observe that longer $\mathrm{WO}_{3}$ needles have a slower charge extraction than shorter needles (Figure 6a), confirming that the issue is related to transport through the material, rather than interfacial defects at the contact. We propose that this slow electron extraction is due to the trapping of electrons below the conduction band and suggest that the mobility of electrons is thereby reduced. The negative correlation of rate of extraction with increasing anodic bias (Figure 5c,d) supports a trap-mediated transport mechanism. As the anodic bias is increased, an increasing number of progressively deeper states below the conduction band are emptied and thus become accessible to trap photoexcited electrons. With greater applied bias, both the density and the depth of these available electron traps in the space charge layer increases. It follows that the electron extraction is slowed because electrons trap and de-trap to reach the back contract, effectively hopping through the needle. This model is consistent with the observation that shorter needles have a faster extraction time, as the distance to the contact is reduced and so fewer trapping/de-trapping steps are required. The fitting of the TDR electron decay to a stretched exponential gives further analytical grounding that supports this transport mechanism, as it indicates the dispersive time range in which electrons are extracted due to multiple trapping steps (Figure S8) ${ }^{77}$ This trapping and de-trapping form of transport has previously been explored with stretched exponential functions or power law decays in other metal oxide based systems. ${ }^{78,79}$ It has also been tentatively proposed by Lindquist's group, ${ }^{30}$ and is consistent with the presence of interband states in $\mathrm{WO}_{3}$ as confirmed in other studies. ${ }^{29,60}$ As previously acknowledged, tungsten trioxide has a large propensity to form numerous oxygen vacancy defects. ${ }^{56,58,68,80}$ It is therefore highly probable that these chemical defects form the interband states responsible for trapping electrons. This is supported herein by the improvement in extraction time observed when the $\mathrm{WO}_{3}$ is subjected to prolonged annealing in air (Figure 6b): with increased opportunity provided for oxygen to permeate the $\mathrm{WO}_{3}$ structure and fill/remove such oxygen vacancies, longer annealing results in fewer trap sites to hinder the transport of electrons to the contact. Furthermore, the lack of photocurrent in the un-annealed sample (Figure S3b) suggests that excessive concentrations of oxygen vacancies trap electrons so strongly and impede the charge carrier mobility to such an extent that most charges recombine. A model of electron dynamics for $\mathrm{WO}_{3}$ needles is summarised in Scheme 1 .

As evidenced in the bias dependence study (Figure 5a,b), we find, depending upon applied bias, that the majority of electrons observed on these microsecond to second timescales are eventually extracted, negating the possibility that a slow, trap-mediated recombination is predominantly being monitored. The lack of 
substantial recombination losses observed in the electron kinetics across these timescales $(0.01 \mathrm{~ms}$ to $1 \mathrm{~s})$ is supported by consideration of the internal quantum efficiencies obtained for the longer and shorter $\mathrm{WO}_{3}$ needles (Figure S6) which remain similar under front illumination, despite the difference in electron extraction times shown in Figure 6a. Modest back electron-hole (surface) recombination is observed for anodic potentials close to flat-band, however this is readily removed by applied potentials $>1.15 \mathrm{~V}$ vs RHE. The lower back electron-hole recombination losses compared to other metal oxide photoanodes such as $\mathrm{BiVO}_{4}$ and $\mathrm{Fe}_{2} \mathrm{O}_{3}$ is most likely due the faster water oxidation kinetics by $\mathrm{WO}_{3}$ holes, as discussed above, which will result in less hole accumulation at the surface under conditions of steady-state photoelectrochemical water oxidation. ${ }^{8,36}$ On the other hand, the extensive electron trapping and associated slow electron transport kinetics observed for the $\mathrm{WO}_{3}$ photoanodes studied herein can be expected to lead to internal resistance losses which will limit the fill factor of the $\mathrm{J} / \mathrm{V}$ curve in a tandem cell device. Given the relatively efficient electron extraction observed for these $\mathrm{WO}_{3}$ photoanodes, we can conclude that ultrafast bulk recombination is the most probable factor limiting device internal quantum efficiency.
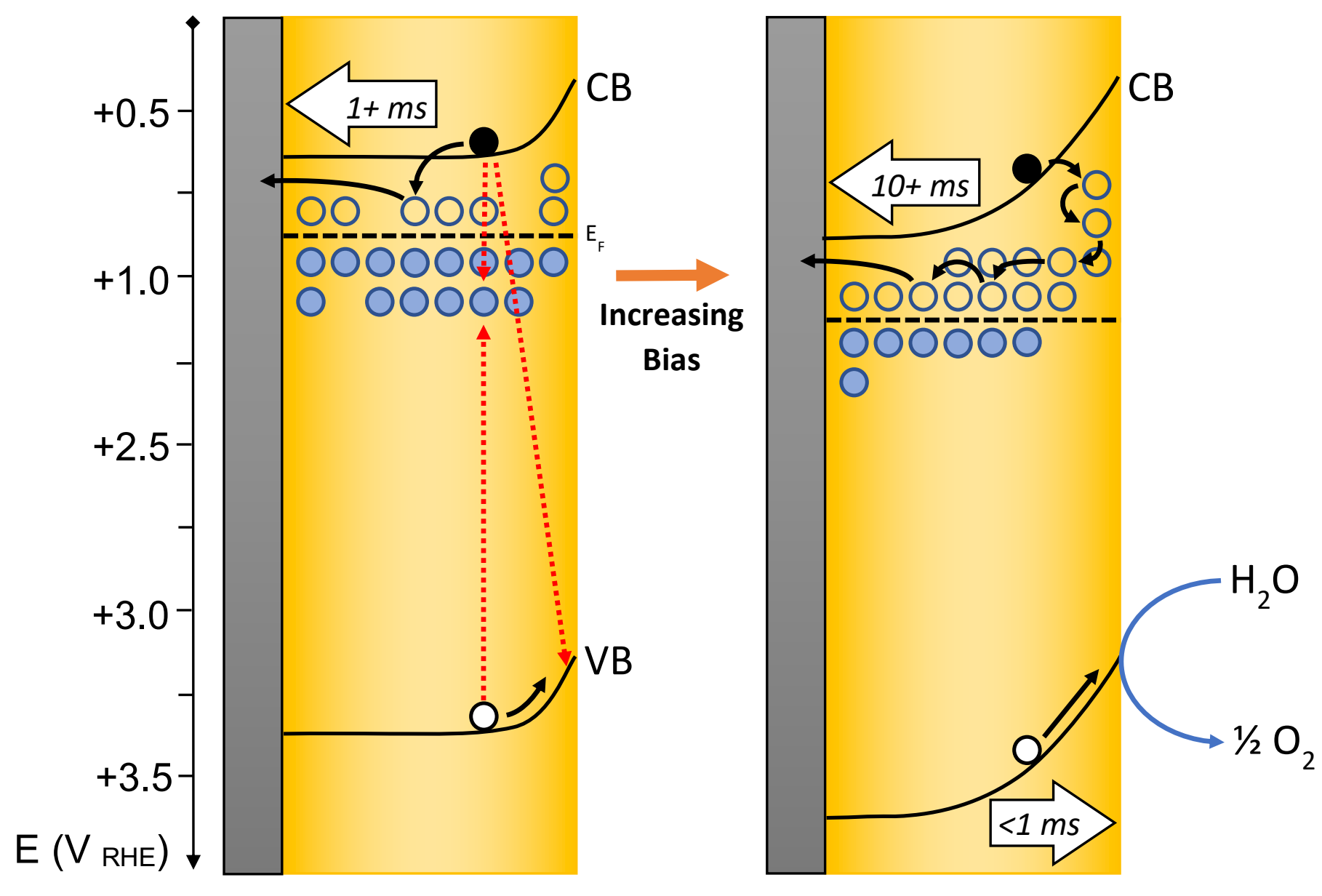
Scheme 1: Photogenerated electrons (black) have different extraction times depending on the applied potential. This is due to the increased number of traps that are empty under bias and hence can accept electrons (open circles). Electrons navigate through these states to the external circuit as indicated by the black arrows. Little recombination, either from the surface or via the trap states (red arrows), is observed on the timescales of the experiment as photogenerated holes (white) are rapid transported to the surface to oxidise water within milliseconds. Left; $0.8 \mathrm{~V}_{\mathrm{RHE}}$, Right; $1.45 \mathrm{~V}_{\mathrm{RHE}}$.

In summary, we have shown our $\mathrm{WO}_{3}$ needles to be rapid water oxidation photoanodes, with high faradaic efficiency and faster hole injection into the electrolyte than in other commonly studied transition metal oxide photoanodes. These rapid water oxidation kinetics improve catalytic performance by supressing competing surface recombination and enabling photocurrent onset close to flat-band without added cocatalysts; we propose that the kinetics correlate with the depth of the valence band. The extraction of electrons, on the other hand, is observed to be particularly slow, which we assign to trapping of electrons into vacant defects below the conduction band. We propose that these trap sites are vacant oxygen vacancies which form the primary intrinsic dopants in the material. Annealing for longer in air therefore increased the rate of charge extraction by reducing the number of oxygen vacancies. We thus conclude that the density of intrinsic chemical defects, such oxygen vacancies, can have a significant effect on charge transport through nanostructured $\mathrm{WO}_{3}$, with potential implications for other heavily doped materials.

\section{Acknowledgements}

J.R.D acknowledges financial support from the European Research Council (project Intersolar 291482). S.C. would like to thank Imperial College for a Schrödinger Scholarship. L.F. thanks the EU for a Marie Curie fellowship (658270) and S.S. thanks the EPSRC for DTP funding. M.S. thanks the Imperial College President's PhD scholarship scheme and AK thanks Imperial College for a Junior Research Fellowship and the Royal Society for a Research Grant (RSG\R1\180434). 


\section{References}

(1) Hurst, J. K. Science 2010, 328, 315.

(2) Fujishima, A.; Honda, K. Nature 1972, 238, 37.

(3) Roger, I.; Shipman, M. A.; Symes, M. D. Nature Reviews Chemistry 2017, 1, 1.

(4) Ahmed, B.; Kumar, S.; Ojha, A. K.; Donfack, P.; Materny, A. Spectrochimica Acta Part A: Molecular and Biomolecular Spectroscopy 2017, 175, 250.

(5) Huang, Z. F.; Song, J.; Pan, L.; Zhang, X.; Wang, L.; Zou, J. J. Advanced Materials 2015, 27, 5309.

(6) Huang, Z.-F.; Pan, L.; Zou, J.-J.; Zhang, X.; Wang, L. Nanoscale 2014, 6, 14044.

(7) Alexander, B. D.; Kulesza, P. J.; Rutkowska, I.; Solarska, R.; Augustynski, J. Journal of Materials Chemistry 2008, 18, 2298.

(8) Ma, Y.; Pendlebury, S. R.; Reynal, A.; Le Formal, F.; Durrant, J. R. Chemical Science 2014, 5, 2964.

(9) Pendlebury, S. R.; Barroso, M.; Cowan, A. J.; Sivula, K.; Tang, J.; Gratzel, M.; Klug, D.; Durrant, J. R. Chem Commun (Camb) 2011, 47, 716.

(10) Kafizas, A.; Ma, Y.; Pastor, E.; Pendlebury, S. R.; Mesa, C.; Francàs, L.; Le Formal, F.; Noor, N.; Ling, M.; Sotelo-Vazquez, C.; Carmalt, C. J.; Parkin, I. P.; Durrant, J. R. ACS Catalysis 2017, 7, 4896.

(11) Liu, X.; Wang, F.; Wang, Q. Physical Chemistry Chemical Physics 2012, 14, 7894.

(12) Kronawitter, C. X.; Vayssieres, L.; Shen, S.; Guo, L.; Wheeler, D. A.; Zhang, J. Z.; Antoun, B. R.; Mao, S. S. Energy \& Environmental Science 2011, 4, 3889.

(13) Wang, G.; Ling, Y.; Wang, H.; Yang, X.; Wang, C.; Zhang, J. Z.; Li, Y. Energy \& Environmental Science 2012, 5, 6180.

(14) Mi, Q.; Zhanaidarova, A.; Brunschwig, B. S.; Gray, H. B.; Lewis, N. S. Energy \& Environmental Science 2012, 5, 5694.

(15) Kafizas, A.; Godin, R.; Durrant, J. R. In Semiconductors and Semimetals; Mi, Z., Wang, L., Jagadish, C., Eds.; Elsevier: 2017; Vol. 97, p 3.

(16) Huo, N.; Yang, S.; Wei, Z.; Li, J. Journal of Materials Chemistry C 2013, 1, 3999.

(17) Sivula, K.; Formal, F. L.; Grätzel, M. Chemistry of Materials 2009, 21, 2862.

(18) Rao, P. M.; Cai, L.; Liu, C.; Cho, I. S.; Lee, C. H.; Weisse, J. M.; Yang, P.; Zheng, X. Nano Letters 2014, 14, 1099.

(19) Hong, S. J.; Lee, S.; Jang, J. S.; Lee, J. S. Energy \& Environmental Science 2011, 4, 1781.

(20) Shi, X.; Choi, I. Y.; Zhang, K.; Kwon, J.; Kim, D. Y.; Lee, J. K.; Oh, S. H.; Kim, J. K.; Park, J. H. Nature Communications 2014, 5, 4775.

(21) Sivula, K.; Le Formal, F.; Grätzel, M. ChemSusChem 2011, 4, 432.

(22) Katoh, R.; Furube, A.; Yamanaka, K.-i.; Morikawa, T. The Journal of Physical Chemistry Letters 2010, 1, 3261.

(23) Zheng, H.; Ou Jian, Z.; Strano, M. S.; Kaner, R. B.; Mitchell, A.; Kalantar-Zadeh, K. Advanced Functional Materials 2011, 21, 2175.

(24) Deb, S. K. Solar Energy Materials and Solar Cells 2008, 92, 245.

(25) Zhu, T.; Chong, M. N.; Chan, E. S. ChemSusChem 2014, 7, 2974.

(26) Patel, K. J.; Panchal, C. J.; Kheraj, V. A.; Desai, M. S. Materials Chemistry and Physics 2009, 114, 475.

(27) Regragui, M.; Jousseaume, V.; Addou, M.; Outzourhit, A.; Bernéde, J. C.; El Idrissi, B. Thin Solid Films 2001, 397, 238.

(28) Johansson, M. B.; Mattsson, A.; Lindquist, S.-E.; Niklasson, G. A.; Österlund, L. The Journal of Physical Chemistry C 2017, 121, 7412. 
(29) Johansson, M. B.; Kristiansen, P. T.; Duda, L.; Niklasson, G. A.; Österlund, L. Journal of Physics: Condensed Matter 2016, 28, 475802.

(30) Wang, H.; Lindgren, T.; He, J.; Hagfeldt, A.; Lindquist, S.-E. The Journal of Physical Chemistry B 2000, 104, 5686.

(31) Smith, A. M.; Kast, M. G.; Nail, B. A.; Aloni, S.; Boettcher, S. W. Journal of Materials Chemistry A 2014, 2, 6121.

(32) O'Neill, S.; Parkin, I. P.; Clark, J. H.; Mills, A.; Elliott, N. Chemical Vapor Deposition 2004,

10, 136.

(33) Barroso, M.; Pendlebury, S. R.; Cowan, A. J.; Durrant, J. R. Chemical Science 2013, 4,

2724.

(34) Sachs, M.; Pastor, E.; Kafizas, A.; Durrant, J. R. The Journal of Physical Chemistry Letters 2016, 7, 3742.

(35) Hisatomi, T.; Minegishi, T.; Domen, K. Bulletin of the Chemical Society of Japan 2012, 85,

647.

(36) Le Formal, F.; Pendlebury, S. R.; Cornuz, M.; Tilley, S. D.; Gratzel, M.; Durrant, J. R. Journal of the American Chemical Society 2014, 136, 2564.

(37) Kim, T. W.; Choi, K.-S. Science 2014, 343, 990.

(38) Klahr, B.; Gimenez, S.; Fabregat-Santiago, F.; Hamann, T.; Bisquert, J. Journal of the American Chemical Society 2012, 134, 4294.

(39) Cristino, V.; Marinello, S.; Molinari, A.; Caramori, S.; Carli, S.; Boaretto, R.; Argazzi, R.; Meda, L.; Bignozzi, C. A. Journal of Materials Chemistry A 2016, 4, 2995.

(40) Amano, F.; Ishinaga, E.; Yamakata, A. The Journal of Physical Chemistry C 2013, 117,

22584.

(41) Kim, J.; Lee, C. W.; Choi, W. Environmental Science \& Technology 2010, 44, 6849.

(42) Tanaka, A.; Hashimoto, K.; Kominami, H. Journal of the American Chemical Society 2014, 136, 586.

(43) Sun, S.; Watanabe, M.; Wu, J.; An, Q.; Ishihara, T. Journal of the American Chemical Society 2018, 140, 6474.

(44) Mendieta-Reyes, N. E.; Díaz-García, A. K.; Gómez, R. ACS Catalysis 2018, 8, 1903.

(45) Kim, T. W.; Choi, K.-S. Science 2014, 343, 990.

(46) Kafizas, A.; Francàs, L.; Sotelo-Vazquez, C.; Ling, M.; Li, Y.; Glover, E.; McCafferty, L.;

Blackman, C.; Darr, J.; Parkin, I. The Journal of Physical Chemistry C 2017, 11, 5983.

(47) Naatz, H.; Hoffmann, R.; Hartwig, A.; La Mantia, F.; Pokhrel, S.; Mädler, L. The Journal of Physical Chemistry C 2018, 122, 2796.

(48) Le Formal, F.; Sivula, K.; Grätzel, M. The Journal of Physical Chemistry C 2012, 116,

26707.

(49) Le Formal, F.; Tetreault, N.; Cornuz, M.; Moehl, T.; Gratzel, M.; Sivula, K. Chemical

Science 2011, 2, 737.

(50) Abdi, F. F.; van de Krol, R. The Journal of Physical Chemistry C 2012, 116, 9398.

(51) Li, G.; Varga, T.; Yan, P.; Wang, Z.; Wang, C.; Chambers, S. A.; Du, Y. Physical Chemistry Chemical Physics 2015, 17, 15119.

(52) Pesci, F. M.; Cowan, A. J.; Alexander, B. D.; Durrant, J. R.; Klug, D. R. The Journal of Physical Chemistry Letters 2011, 2, 1900.

(53) Pendlebury, S. R.; Cowan, A. J.; Barroso, M.; Sivula, K.; Ye, J.; Gratzel, M.; Klug, D. R.; Tang, J.; Durrant, J. R. Energy \& Environmental Science 2012, 5, 6304.

(54) Dotan, H.; Sivula, K.; Gratzel, M.; Rothschild, A.; Warren, S. C. Energy \& Environmental Science 2011, 4, 958. 
18370.

(55) Zhong, D. K.; Choi, S.; Gamelin, D. R. Journal of the American Chemical Society 2011, 133,

(56) Gillet, M.; Lemire, C.; Gillet, E.; Aguir, K. Surface Science 2003, 532, 519.

(57) Berak, J. M.; Sienko, M. J. Journal of Solid State Chemistry 1970, 2, 109.

(58) Greiner, M. T.; Chai, L.; Helander, M. G.; Tang, W.-M.; Lu, Z.-H. Advanced Functional Materials 2012, 22, 4557.

(59) Ling, Y.; Wang, G.; Wang, H.; Yang, Y.; Li, Y. ChemSusChem 2014, 7, 848.

(60) Chatten, R.; Chadwick, A. V.; Rougier, A.; Lindan, P. J. D. The Journal of Physical Chemistry B 2005, 109, 3146.

(61) Allpress, J. G.; Tilley, R. J. D.; Sienko, M. J. Journal of Solid State Chemistry 1971, 3, 440.

(62) Hutchins, M. G.; Kamel, N. A.; El-Kadry, N.; Ramadan, A. A.; Abdel-Hady, K. physica status solidi (a) 1999, 176, 991. 391, 654.

(63) Li, Y.; Wang, C.; Zheng, H.; Wan, F.; Yu, F.; Zhang, X.; Liu, Y. Applied Surface Science 2017,

(64) Daijiro, T.; Makoto, I.; Yasuhiro, S.; Takayoshi, H.; Nobuyuki, I.; Shunsuke, T.; Takayuki, H. Chemistry - A European Journal 2011, 17, 9816.

(65) Gardecka, A. J.; Bishop, C.; Lee, D.; Corby, S.; Parkin, I. P.; Kafizas, A.; Krumdieck, S. Applied Catalysis B: Environmental 2018, 224, 904.

(66) Lin, Y.; Yuan, G.; Sheehan, S.; Zhou, S.; Wang, D. Energy \& Environmental Science 2011, $4,4862$. 2009, 113, 772 .

(67) Cesar, I.; Sivula, K.; Kay, A.; Zboril, R.; Grätzel, M. The Journal of Physical Chemistry C

(68) Jones, F. H.; Rawlings, K.; Foord, J. S.; Cox, P. A.; Egdell, R. G.; Pethica, J. B.; Wanklyn, B. M. R. Physical Review B 1995, 52, R14392.

(69) Tachibana, Y.; Vayssieres, L.; Durrant, J. R. Nature Photonics 2012, 6, 511.

(70) Smith, R. D. L.; Prévot, M. S.; Fagan, R. D.; Zhang, Z.; Sedach, P. A.; Siu, M. K. J.; Trudel, S.; Berlinguette, C. P. Science 2013, 340, 60.

$7,752$.

(71) Cao, D.; Luo, W.; Feng, J.; Zhao, X.; Li, Z.; Zou, Z. Energy \& Environmental Science 2014,

(72) Glasscock, J. A.; Barnes, P. R. F.; Plumb, I. C.; Savvides, N. The Journal of Physical Chemistry C 2007, 111, 16477.

(73) Tilley, S. D.; Cornuz, M.; Sivula, K.; Grätzel, M. Angewandte Chemie 2010, 122, 6549.

(74) Zhong, D. K.; Sun, J.; Inumaru, H.; Gamelin, D. R. Journal of the American Chemical Society 2009, 131, 6086.

(75) Su, J.; Guo, L.; Bao, N.; Grimes, C. A. Nano Letters 2011, 11, 1928.

(76) Hoang, S.; Guo, S.; Hahn, N. T.; Bard, A. J.; Mullins, C. B. Nano Letters 2012, 12, 26.

(77) Sturman, B.; Podivilov, E.; Gorkunov, M. Physical Review Letters 2003, 91, 176602.

(78) Nelson, J.; Chandler, R. E. Coordination Chemistry Reviews 2004, 248, 1181.

(79) van de Lagemaat, J.; Frank, A. J. The Journal of Physical Chemistry B 2000, 104, 4292.

(80) Granquist, C. G. Solar Energy Materials and Solar Cells 2000, 60, 201. 
Table of Contents Graphic

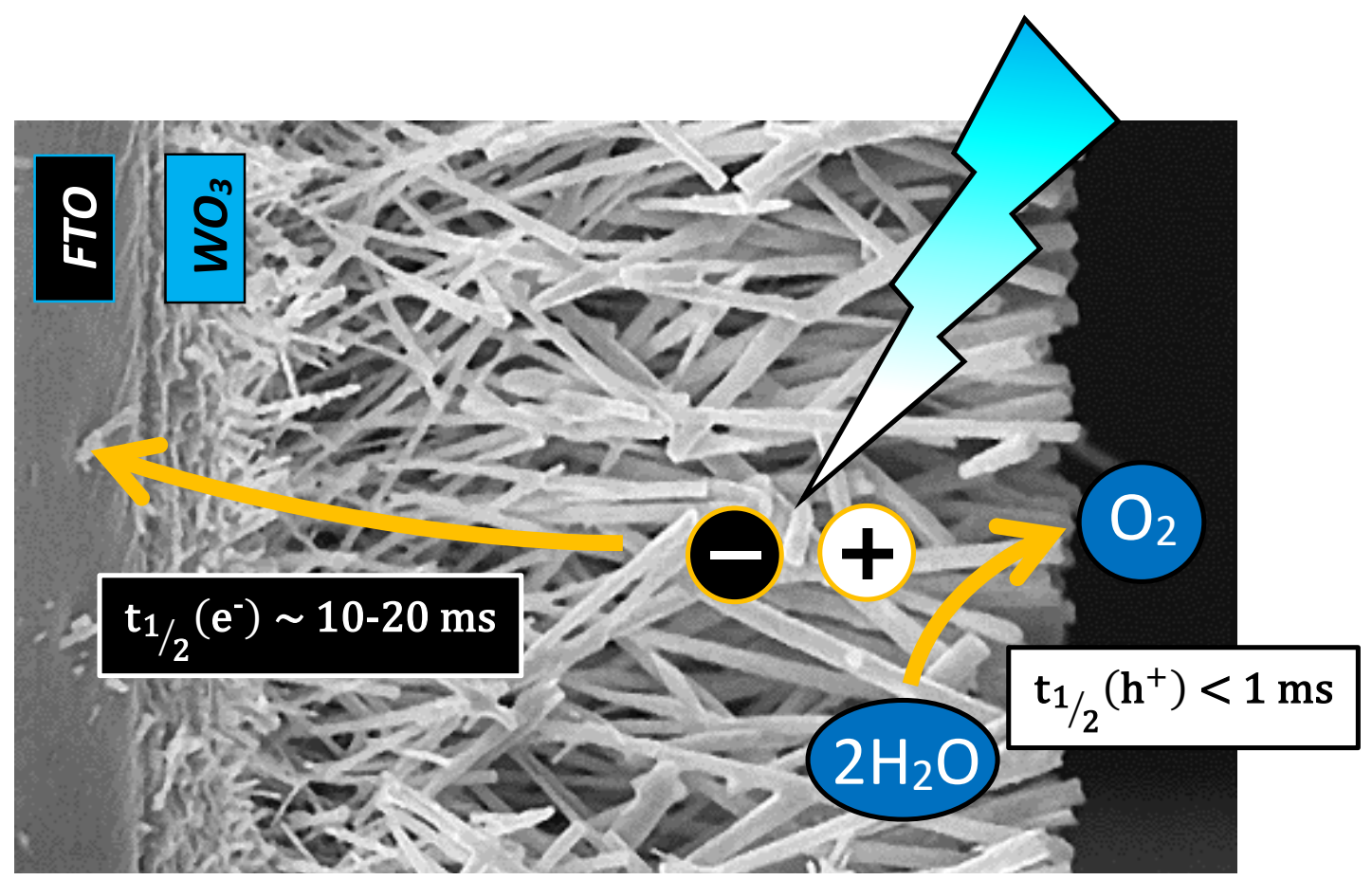

